\title{
Elastic buckling of thin plate with circular holes in bending
}

\author{
Guo Yanli ${ }^{1,2}$, Song Xiaoqing ${ }^{1 *}$, Li Xiao ${ }^{1}$, Yao Xingyou ${ }^{1,2}$, Xia Zhifan $^{1,2}, \mathrm{Xu} \mathrm{Bin}^{1,2}$, Su Jianyi ${ }^{1}$ \\ ${ }^{1}$ School of Civil and Architectural Engineering, Nanchang Institute of Technology, Nanchang, 330099, China; \\ ${ }^{2}$ Jiangxi Province Key Laboratory of Hydraulic \& Civil Engineering Infrastructure Security, Nanchang, 330099, China
}

\begin{abstract}
Stress redistribution will occur around the hole for the perforated plate under bending, and the buckling mode of bending plate is changed, which makes the design of bending plate more complicated. The finite element software ABAQUS is used to establish the perforated plate under bending model, analyze the degree of influence of the plate aspect ratio, width-thickness ratio, size and position of the holes, meanwhile, the distance between holes is also discussed. The results show that the thickness of the plate size and width-thickness ratio have little influence on the elastic buckling performance of thin plates with holes in bending. As the size of the holes increase, the influence is greater, and there is a certain regularity. The opening position is closer to the short side of the plate, the buckling coefficient of plate will be significantly decreased. The effect is greater with the increase of opening size, the distance between holes have a safe value, the position of the opening is more obvious for the buckling of the bending plate. Finally, based on the data from finite element analysis, the proposed formula of buckling stability coefficient $\mathrm{k}$ for the bending perforated plate is given.
\end{abstract}

\section{Introduction}

Cold-formed thin-walled steel with high anti-corrosion, light weight, simple laying, high strength and good ductility, has many ideal properties required by building materials, and is a green building product in line with the sustainable development of the world [1]. However, the hole opening on the cold bending plate is to make it easy to set up horizontal support, pipeline path and so on. The stress redistribution of the plate opening will often make the design more complicated.

At present, there are few researches on the bending plate of cold-formed thin-walled steel. He [2] conducted an experimental study on the bearing capacity performance of cold-formed thin-walled steel members subjected to bending, comparing the test value with the standard theoretical value, and the results show that the calculated value is safe. Yao [3-5] studied the elastic buckling of cold-formed thin-walled steel flexural member members in detail by using theoretical and finite element programs, and proposed a calculation method of elastic buckling stability coefficient of flexural members. Wang [6] studied the bending member of cold-formed thin-walled steel with holes in the web and found that the ultimate bearing capacity of the specimens was reduced to varying degrees by opening. shanmuagam [7] studied the buckling behavior of the perforated plate under uniaxial or biaxial compression under different boundary conditions, analyzed the plate with the finite element method, and determined the design formula of the ultimate bearing capacity. El-sawy [8] studied the effect of length-width ratio on the elastic buckling of eccentric uniaxial loading plates. Moen [9] summarized the approximate expression of the critical elastic buckling stress of a bullet hole or a porous plate during bending or compression. When the effective width method is used in the specification of our country to calculate the bearing capacity of cold-formed thin-walled steel, the buckling stability coefficient should be calculated firstly, and based on the elastic buckling coefficient of the single plate, the effective width of the whole member is finally obtained after taking into account the correlation between plates. In this paper, the finite element software ABAQUS is used to analyze the elastic buckling behavior of thin plates with open holes in bending, and a simple formula for calculating the elastic local buckling stability coefficient of the sheet with curved holes was proposed.

\section{Establishment of finite element model of perforated thin plate}

\subsection{Definition of basic parameters for perforated thin plates}

Based on the finite element software ABAQUS, the model of open hole bending plate is established as shown in figure 1 . The length of the rectangular thin plate is a, the width of the plate is $b$, the thickness of the thin plate is $t$, the diameter of the round hole is $d$, the distance between holes is $\mathrm{S}$, the number of long round holes is $n$, the number of round holes is $\mathrm{m}$, the distance

*Corresponding author's email: 1846715496@qq.com 
between the center of circular hole and the short side of rectangular plate is $\mathrm{x}_{\mathrm{e}}$, and the width-thickness ratio of plate is $b / t=100$. The main analysis parameters include:length-width ratio(a/b), width-thickness ratio(b/t), opening shape, opening size $(d / b)$, hole spacing $(S / d)$ and position $\left(\mathrm{x}_{\mathrm{e}} / \mathrm{d}\right)$. On the basis of parameter analysis, the proposed formula for calculating the buckling stability coefficient $\mathrm{k}$ of the plate with bent opening is given.

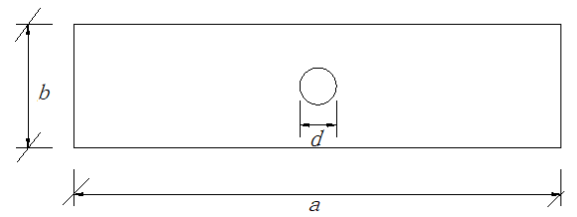

(a) the center of the web opens with a round hole

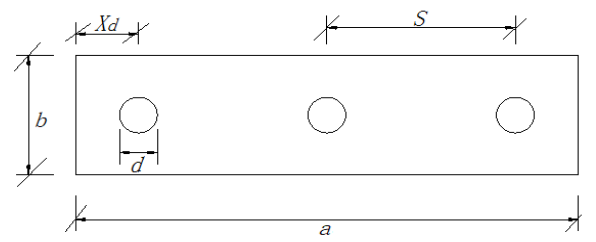

(b)open three round holes

Figure1. The dimension of groove section and the form of opening at the specimen web

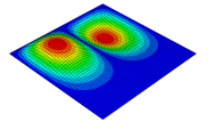

(a) $a / b=1$ plate

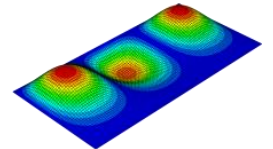

(b) $a / b=2$ plate

\subsection{Establishment of finite element model of thin plate and its validity verification}

The elastic modulus $\mathrm{E}=206 \mathrm{GPa}$, Poisson's ratio $\mathrm{v}=0.3$, plastic shell element is used to constrain $U_{y}$ around the model, constrain $U_{x}$ on both sides of $\mathrm{Z}$ direction, and constrain $U_{z}$ direction in the middle of the model. The loading formula of the unit load on both sides of the model $\mathrm{Z}$ direction.



(a)finite element model

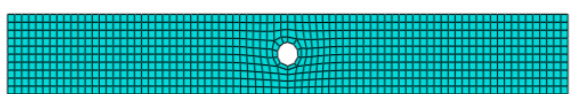

(b) mesh generation

Figure 2. finite element model of opening plate

In order to verify the validity of the proposed model, the results $\sigma_{\mathrm{a}}$ of finite element buckling analysis of plates with no openings are compared with the results of $\sigma_{\mathrm{cr}}$ calculated by the classical elastic buckling stress formula (1). The calculation formula is as follows:

$$
\sigma_{c r}=k \frac{\pi^{2} E}{12\left(1-v^{2}\right)}\left(\frac{t}{b}\right)^{2}
$$

For bent plates, $\mathrm{k}=23.87$.

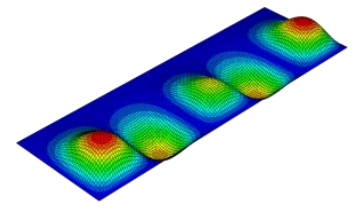

(c) $a / b=3$ plates

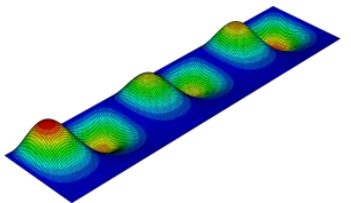

(d) $\mathrm{a} / \mathrm{b}=4$ plates

Figure 3. Buckling modes of unperforated axial compression plates with different length-width ratios

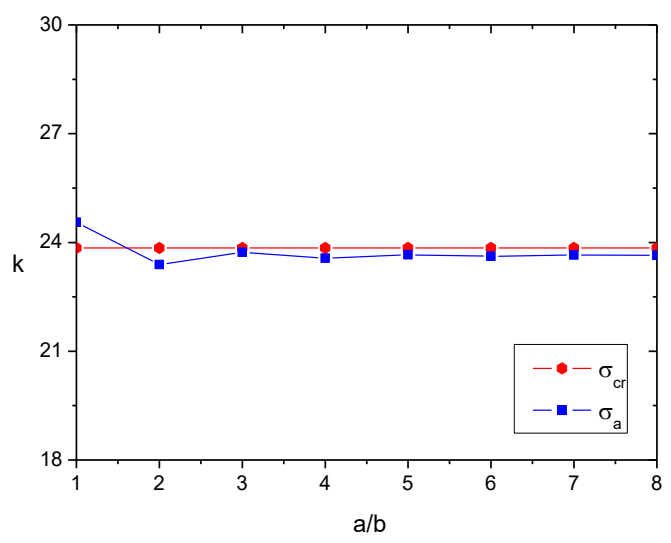

Figure 4. Comparison of finite element analysis $\sigma_{a}$ of unperforated plate and the calculation formula results $\sigma_{c r}$

Figure 4 shows the finite element buckling mode diagram of bending plate parts with different length-width ratios $(\mathrm{a} / \mathrm{b})$. Comparing the numerical results of finite element analysis with those of formula calculation, it is shown that the finite element analysis results of cold-formed thin-walled steel bending plate with no opening are in good agreement with the results of classical calculation formula of elastic buckling stress.

\section{Elastic buckling of flexural plates with round hole}

\subsection{Effect of aspect ratio on buckling of single hole plate}

In order to study the influence of the thickness-ratio $(b / t)$ on perforated bending plate, the thickness ratio $(\mathrm{b} / \mathrm{t})$ was taken as $50,100,150$. A hole is opened in the middle of the plate, and the ratio of hole diameter to plate width $(\mathrm{d} / \mathrm{b})$ changes from 0.1 to 0.8 . The analysis results are as follows: 


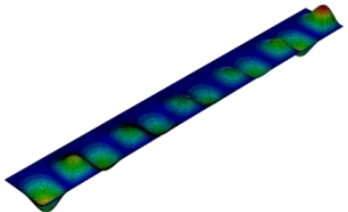

(a) $d / b=0.1$

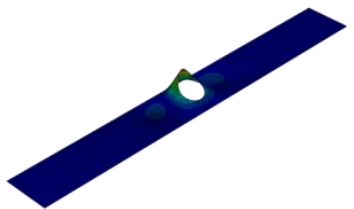

(e) $d / b=0.5$

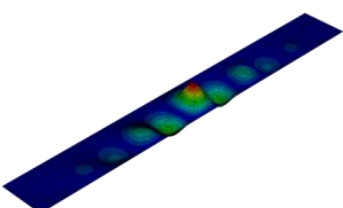

(b) $d / b=0.2$



(c) $\mathrm{d} / \mathrm{b}=0.3$

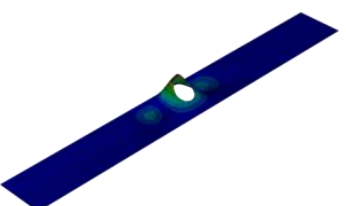

(d) $d / b=0.4$



(f) $d / b=0.6$

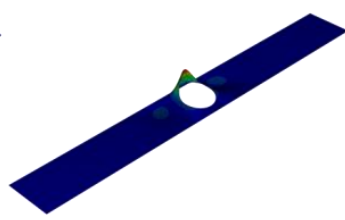

$(\mathrm{g}), \mathrm{d} / \mathrm{b}=0.7$

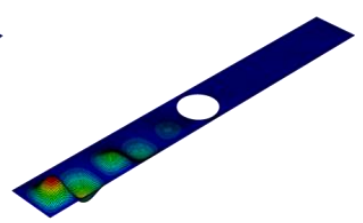

(h) $\mathrm{d} / \mathrm{b}=0.8$

Figure 5. Buckling modes of open single circular hole

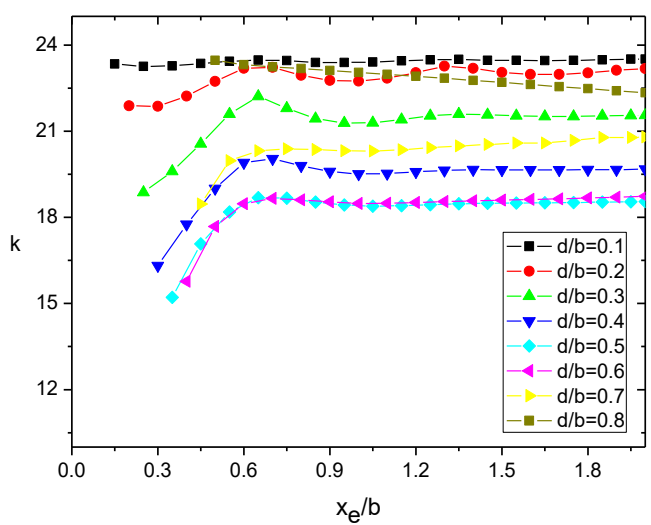

Figure 6. The change law of the $\mathrm{k}$ value of the buckling coefficient of a single circular orifice plate

Figure 6 is a data diagram of finite element buckling analysis of flexural plate members with $a / b=8$, the ratio of hole diameter to plate width $(\mathrm{d} / \mathrm{b})$ changing from 0.1 to 0.8 , and $\mathrm{x}_{\mathrm{e}} / \mathrm{b}$ changing from small to large.

From the variation law shown in Fig. 6, the buckling coefficient $\mathrm{K}$ of the bending plate tends to be stable after $\mathrm{x}_{\mathrm{e}} / b \geq 1.0$. The buckling coefficient $\mathrm{K}$ value is generally



(a) $n=3$

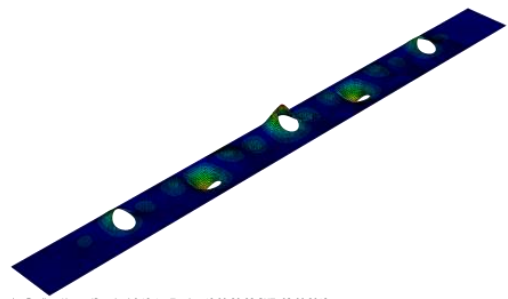

(b) $n=5$ low when the hole is opened in the area of $\mathrm{x}_{\mathrm{e}} / b \leq 0.7$, and the influence degree increases with the increase of the hole diameter. And for bending plate, the buckling coefficient $\mathrm{K}$ value of small hole diameter is not necessarily larger than that of large hole diameter when the hole is opened at the same position. In summary, it is suggested that the hole location should be in the region of $\mathrm{x}_{\mathrm{e}} / b \geq 0.7$ as far as possible. If the hole is to be opened in the region of $x_{\mathrm{e}} / b \leq 0.7$, it is suggested that the hole diameter should be limited to $d / b \leq 0$.3in order to prevent the safety of the plate structure caused by the small buckling stability factor $\mathrm{K}$ of the bending plate.

\subsection{Elastic buckling of bending plate with multi-round holes}

On the basis of the study of bending plate with single circular hole, equidistant multi-circular holes are opened along the $\mathrm{x}$-axis. The number of holes includes $\mathrm{n}=3,5,7$. The buckling mode is shown in Figure 7.

Figure 7.Buckling modes of plates with multiple circular holes

For the study on the opening of multi-round holes of the bending plate part, we first study the effect of the distance from the center of the most lateral hole to the shorter side of the plate on the buckling coefficient $\mathrm{k}$. The bending plate with five circular holes is selected. the lateral side between two hole plate, the plate end distance $\left(\mathrm{x}_{\mathrm{e}} / \mathrm{b}\right)$ varying from 0.5 to 3.5 , the rest of the hole fixed to $200 \mathrm{~mm}$, the distance between the hole size $(d / b)$ of 0.1 to 0.7 . The results are as follows: 


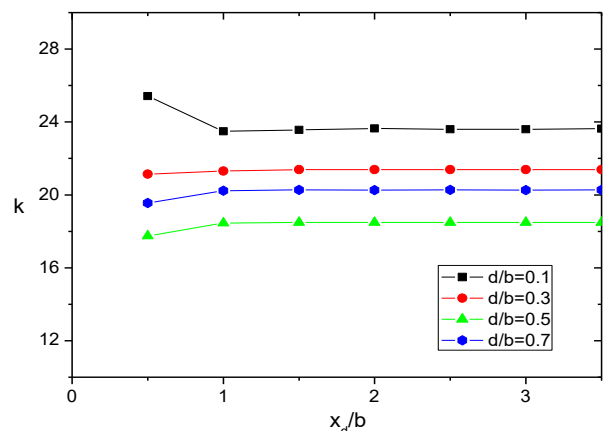

Figure 8. Plate end distance $(\mathrm{xd} / \mathrm{b})$ influence on the buckling coefficient $\mathrm{k}$ of porous plate

From the change rule of Figure 8, it is known that the buckling coefficient $K$ tends to be stable at $x_{d} / b \geq 1$. For the stability coefficient $\mathrm{k}$ value of bending plate parts, the stability of plate parts for opening holes can only be ensured when $\mathrm{k} \geq 18$. When the gap between the two most lateral holes is small, the buckling coefficient $\mathrm{k}$ is generally relatively small and the bending plate parts are unsafe. Therefore, according to the previous research results, the plate end distance will be set as the constant value $x_{d} / b=2$ to ensure the safety of the bending plate. The number of holes was set as $n=5$, the size of holes $(\mathrm{d} / \mathrm{b})$ changed from 0.2 to 0.8 , and the spacing $(\mathrm{S} / \mathrm{d})$ changed from 2 to 10 . The analysis results are as Figure 9.

According to the change rule in Figure 9, after selecting the safe value of the plate end distance, we suggest that the hole spacing $s / d \geq 4$, so as to guarantee the safety of the structure of the plate part. Meanwhile, in order to analyze the influence of the number of holes on the buckling coefficient $\mathrm{k}$, take the number of holes $n=3,5$ and 7 and fix the plate end distance $X d / b=2$. The analysis results are as follows:

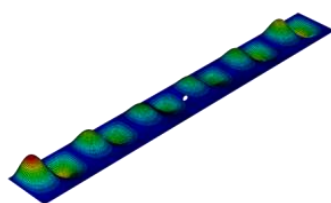

(a) $d / b=0.1$

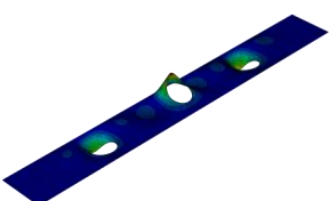

(e) $d / b=0.5$



(b) $\mathrm{d} / \mathrm{b}=0.2$



(f) $d / b=0.6$

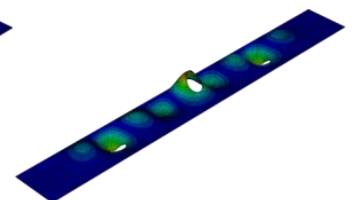

(c) $\mathrm{d} / \mathrm{b}=0.3$

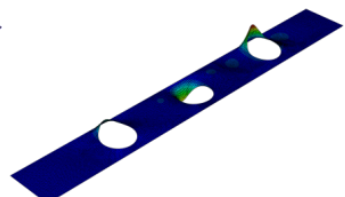

(g), d/b $=0.7$

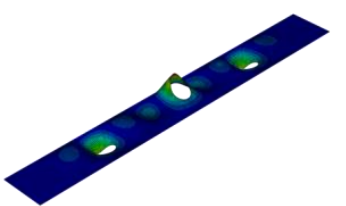

(d) $d / b=0.4$



(h) $\mathrm{d} / \mathrm{b}=0.8$

Figure 11. Influence of opening 3 circular holes on the buckling coefficient $\mathrm{k}$ of perforated plate 


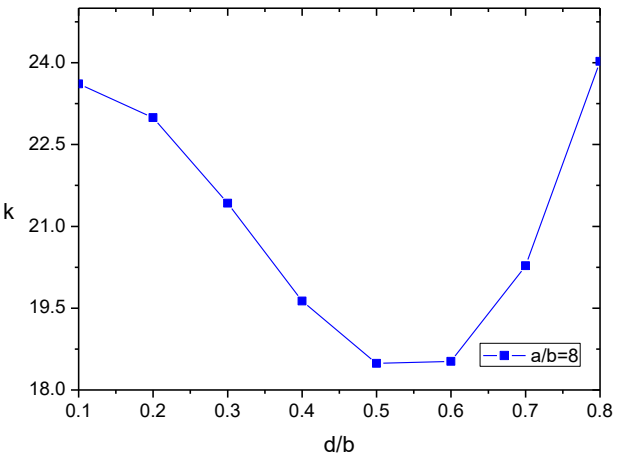

Figure 12. influence of 3 circular holes on buckling coefficient $\mathrm{k}$ of perforated plate

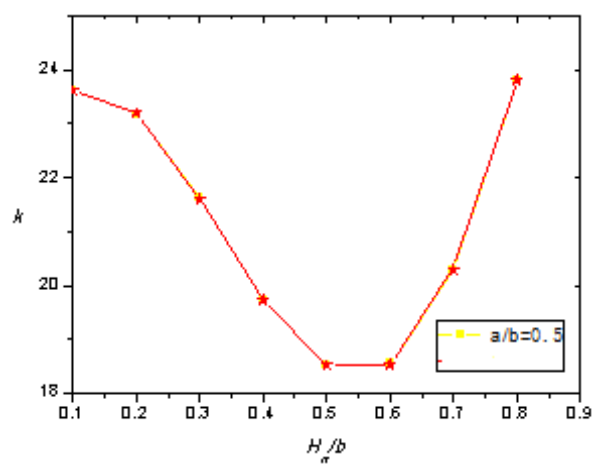

Fig. 13 effect of single hole (d/b) on buckling coefficient $k$ of open plate

As can be seen from figure 12, with the increase of the diameter of the hole, the buckling stability coefficient of the plate decreases. However, after $\mathrm{d} / \mathrm{b}>0.5$, due to the increase of the width/thickness ratio of the edge part of the plate with the hole, the buckling gradually turns to buckling at the position of non-hole, and the buckling coefficient continues to increase.

\section{Suggestions for elastic buckling design of perforated plate}

Through the finite element software ABAQUS, we know that the hole size $(d / b)$, plate end spacing $\left(x_{d} / b\right)$ have the buckling coefficients of bending plates with opening.

By comparing and analyzing the finite element analysis data of thin plate with single circular hole, figure 22 is concluded. The figure is plotted by the buckling coefficient from 0 to 0.8 when the length/width ratio of different plate parts is $\mathrm{a} / \mathrm{b}=5$.

Based on the results of finite element analysis, the elastic buckling coefficient $\mathrm{k}$ of the plate with round hole can be calculated by the following formula (2):

$$
k_{1}=\left\{\begin{array}{l}
23.9\left[-0.57\left(\frac{d}{b}\right)^{2}-0.23\left(\frac{d}{b}\right)+1.029\right]\left(\frac{d}{b}\right) \leq 0.5 \\
23.9\left[3.65\left(\frac{d}{b}\right)^{2}-4.01\left(\frac{d}{b}\right)+1.864\right] 0.5 \leq\left(\frac{d}{b}\right) \leq 0.8
\end{array}\right.
$$

\section{Conclusion}

In this paper, finite element analysis software ABAQUS was used to calculate and analyze the influence of opening hole on the buckling coefficient of the bending plate, and the influence of opening position, opening shape and opening size on the buckling stability coefficient $\mathrm{k}$ of the bending plate was studied. The following conclusions can be drawn:

(1)For the bending plate with single circular hole, this paper suggests limiting the opening position to the area where $x_{d} / b \geq 0.7$; for the bending plate with multiple circular holes, it is suggested that the end spacing of the plate should be controlled in the area where $x_{d} / b \geq 2.0$, so as to ensure the safety of the bending plate with multiple circular holes.

(2) Through the finite element analysis, obtain the proposed formulas corresponding to the size $(\mathrm{d} / \mathrm{b})$ of a single circular hole. The proposed formulas are consistent with the finite element analysis results, which can ensure the safety of the calculated results.

\section{Ackonwledgement}

The author gratefully acknowledgements the financial support provided by Department of Education Science and Technology Projects of Jiangxi Province in China (No, GJJ180932, GJJ170983), National Natural Science Foundation Projects of China (No:51868049), Natural Science Foundation Projects of Jiangxi Province in China (No:20181BAB206040), and Academic and Technical Leaders in Major Subject Areas projects of Jiangxi Province in China(No: 20172BCB22022).

\section{References}

1. Zhou. X.H. (2009) Stability theory of thin-walled member and its application. Science press.

2. He B.K., Sun Y.A., Su M.Z. (2009) Experimental Study and Theoretical Analysis on Load Carrying apacity of Cold-Formed Flexural Members with Thicknesses Less Than 2mm. Structure Engineering.66-68+81.

3. Yao X.Y., Guo Y.L. (2017) Distortional Buckling of Cold-Formed Thin-Walled Steel Lipped Channel Bending Members. Architectural Technology.

4. Yao X.Y., Guo Y.L. (2010) Study on Local Buckling Properties of Cold-Formed Thin-Walled Steel Members. Low Temperature Architecture Technology ,48-50.

5. Yao X.Y., Tan Z., Guo Y.L. (2016) Elastic Buckling of Cold-Formed Thin-Walled Steel Lipped Channel Bending Members with Web Openings. Low Temperature Architecture Technology,53 56.

6. Wang C.G., Liang R.J., Zhang z.n. (2014) Experimental investigation on stability behavior of channel flexural members with complex edge stiffeners and web holes. Journal of architectural structure, 131 140.

7. Technical specification for.GB 500015 - 2002(2002) cold-formed thin-walled steel structure of Ministry of construction of People's Republic of China. Beijing: China planning Publishing House. 
8. The vendran SV, Tan YH. (1999) Design formula for axially compressed perforated plates Thin-walled Structures, 1-20.

9. El-Sawy. K.M. (2001) Effect of aspect ratio on the elastic buckling of uniaxially loaded plates with eccentric holes[J]. Thin-Walled Structures, 983-998.

10. Moen. C. D (2009) Elastic buckling of thin plates with holes in compression or bending. Thin-Walled Structures, 1597-1607 